\title{
Die Arlt-Feier in Obergraupen
}

Anläßlich des 50. Todestages Prof. Arlts fanden in seinem Geburtsort aObergraupen am 26. und 27. Juni eine Reihe festlicher Veranstaltungen statt. Sie wurden am 26. Juni, abends, durch eine Festsitzung der Gemeindevertretung eingeleitet, in welcher unter Beisein der fast vollzählig erschienenen Verwandten Arlts und von uns Festgästen das neu errichtete Arlt-Museum als bleibende Einrichtung erklärt und die dazu nötigen Statuten be-schlossen wurden. Am Sonntag, den 27. Juni, wurden nach einer Feldmesse am Mückenberg Kränze am dortigen Friedhofe nieder-gelegt, worauf der Geistliche, ferner Dr. Ferdinand Arlt, ein Enkel Prof. Arlts, kurze Ansprachen hielten. Um 10 Uhr 30 Minuten wurde die Gedenktafel an Arlts Geburtshaus enthüllt, wobei Gymn.-Prof. Müller aus Teplitz in formvollendeter, freier Rede die Persönlichkeit Arlts und seine menschliche Größe schilderte. Dr. Ferdinand Arlt vervollständigte das gegebene Bild des großen Mannes durch Mitteilung persönlicher Erinnerungen. Nach einer gemeinsamen Festtafel im Gasthof auf dem Mückenberge, an dessen Abhang Obergraupen liegt, folgte um 3 Uhr die Eröff-nung des Museums. Sie wurde eingeleitet durch eine kurze Ansprache Direktor Keiths, von dem die Anregung zur Gründung des Museums stammte und der auch die treibende Kraft der gan-zen Feier war. Darauf folgten kurze Ansprachen von Vertretern der verschiedenen Körperschaften, darunter von Prof. Kubik als Vertreter der Prager und von mir als Vertreter der Wiener Uni-versität und der Wiener ophthalmologischen Gesellschaft. Die ganze Festfolge war von sonnigem, windstillem Wetter begün-stigt und hat in ihrer schönen Harmonie wohl bei alien Festgästen einen nachhaltigen Eindruck hinterlassen. Ich selbst, der ich sowohl durch Fuchs wie besonders durch Purtscher senior manches Persönliche von Arlt gehört hatte, bekam erst durch Bekanntwerden mit den biederen, einfachen Ortsbewohnern den richtigen Eindruck davon, wie Arlt wohl als Persönlichkeit ge-wesen sein mag. Der ärmliche Ort selbst hat seit Arlts Zeiten kaum eine Aenderung aufzuweisen. Das Museum ist in dem seinerzeit durch Arlt geschenkten Schulhause untergebracht.

Zum Schlusse sei noch erwähnt, daß eine eigene Festnum-mer der Erzgebirgszeitung (58. Jahrgang, 6. Heft) erschien, in welcher eine Reihe von Berichten über Arlt und seine Vorfahren, ferner die Entwicklung des Ortes, die Art und Beschäftigung seiner Bewohner, die Gegend und anderes enthalten ist. Sie stam-

180 Tagesnachrichten - Bücherbesprechungen

men von Direktor Keith, von Prof. Kubik und dem KatechetenMüller. ～K. Lindner. Tagesnachrichten.

15. Internationaler Kongreß für Ophthalmologíe.

Vom 8. bis zum 14. Dezember 1937 findet, wie schon früher mitgeteilt worden ist, in Kaíro (Aegypten) der 15. Internationale Kongreß für Ophthal-mologie stalt. Die Kongreßleitung bittet um rechtzeitige Anmeldung. Der Teilnehmerbeitrag beträgt 50.-, bzw. 25.- Schweizerfranken. Nähere Auskunft erteilt: The Secretary General, XV Concilium Ophthal-mologicum, B. O. P. Nr. 2001, Cairo (Egypt).

Bücherbesprechungen. 
Dr. med. Otto Löwenstein: Die Stסrungen des Lichtreflexes der Pupille bei den luetischen Erkrankungen des Zentralnervensystems. Benno Schwabe \& Co., Basel.

L. Löwenstein schildert zunächst ausführlich seine kinematographischeUntersuchungsmethodik des Pupillenspiels und die physiologischen Abartender Normalreaktion. - Für die Frühdiagnose der syphilitischen Erkran-kungen des Zentralnervensystems scheinen ihm geringe Abweichungen vomnormalen Bewegungsablauf von großer Bedeutung, die seiner Ansicht nachoft nur mittels der Laufbilduntersuchung sichergestellt werden können. Imeinzelnen werden an solchen Zeichen, die der klinisch ausgeprägten Erkran-kung u. U. lange vorauseilen können, genannt und in Kurven abgebildet:abnorme Erschöpfbarkeit des Lichtreflexes, verschiedenes Verhalten der Ver-engerungs- und Erweiterungsphase, Unterschiede im Ausmaß der direkten undkonsensuellen Reaktion, Veränderungen der Latenzzeit und paradoxe Reak-tion. Auch Kurven der bekannten Formen von Pupillenstarre verschiedenenAusbildungsgrades werden gegeben. - Die Beispiele aus einem Krankengutvon 100 Fallen sind deswegen weniger überzeugend, weil, vielleicht ausGründen der Einprägsamkeit, oft Fälle ausgesucht sind, in denen der klinischeund serologische Befund schon ohne die Pupillenstörungen ziemlich eindeutigdie Diagnose gestattete. Ein weiterer Mangel vom augenärztlichen Standpunktist das Fehlen fast aller Angaben über Sehvermögen, Gesichtsfeld, Augen-bewegungen und Augenhintergrund - Dinge, die für die Beurteilung vonPupillenstörungen doch von recht großer Bedeutung sind. - Ich möchtebezweifeln, ob es zur Feststellung diagnostisch verwertbarer Abweichungenvon der normalen Pupillenbewegung eines auch in seiner vereinfachten Formdoch noch recht umständlichen und kostspieligen Apparates bedarf, wie ihnL. empfiehlt, zumal nur wenige Aerzte die Kühnheit haben werden, allein auseiner nicht eindeutigen Pupillenstörung eine syphilitische Erkrankung desZentralnervensystems zu diagnostizieren. - Ich halte es deshalb für unwahr-scheinlich, daß die Apparatur Löwensteins, deren Wert für physiologischeUntersuchungen der Pupillenbewegungen unbestritten ist, sich beim Praktikerin größerem Umfange einführen wird, obgleich L. sich in seinem Buch geradean diesen ausdrücklich wendet. Kyiieleis (Hamburg). 